\title{
Post-Occupancy Evaluation of Waterfront Space in the Context of Urban Renewal: A Study Case of Reconstruction of Donghaochong River in Guangzhou City
}

\author{
Jianhong Fan"1,2, Xuemei Zhu',2, Junjie Zhang1 \\ ${ }^{1}$ School of Architecture and Urban Planning, Guangdong University of Technology, Guangzhou, China \\ ${ }^{2}$ State Key Laboratory of Subtropical Building Science, South China University of Technology, Guangzhou, China \\ Email: fanjh7576@yeah.net
}

Received 6 May 2016; accepted 18 July 2016; published 21 July 2016

Copyright (C) 2016 by authors and Scientific Research Publishing Inc. This work is licensed under the Creative Commons Attribution International License (CC BY). http://creativecommons.org/licenses/by/4.0/

\section{(c) (i) Open Access}

\begin{abstract}
Taking the Donghaochong River as a study case, the environmental evolution process and spatial characteristics of Donghaochong River are analyzed through field investigation, questionnaire and in-depth interview in the context of urban renewal and combining relevant historical documents and statistical data. From the perspective of users, the behavior characteristics and use demand of surrounding users for waterfront space of Donghaochong River in Guangzhou City and the evaluation of usage situation before and after reconstruction of Donghaochong River are summarized to provide relevant optimization suggestions for the creation of satisfactory waterfront landscape environment for users.
\end{abstract}

Keywords

Waterfront Space, Post-Occupancy Evaluation, River Reconstruction, Urban Renewal

\section{Introduction}

Urban renewal is the main method for the reconstruction of old cities in China. It includes not only the improvement of existing architectural form, spatial layout and environmental function, but also the continuity and renewal of neighborhood social network structure, mental orientation and emotional attachment [1]-[3]. As an 
important part of urban waterfront ecosystem and spatial pattern, river is also the basic spatial place carrying urban regional context and local life, thus river reconstruction has great significance in promoting urban construction taste and improving people's lives. Most rivers in Guangzhou City have gone through cut-off, river bed canalization, river bed filling, transformation to sewage outfall and environment reconstruction. However, the decline and activation of rivers brings the decline and revitalization of waterfront public space in coastal cities. In 2009, on the occasion of the Asian Games, Guangzhou City carried out city image renewal and environment reconstruction with a focus on river environment reconstruction. The reconstruction of rivers in Guangzhou City was carried out from top to bottom, and mainly stopped at the level of promoting the beautification of ecology and landscape [4]-[7]. The correlation between the demands of users and the environmental behavior in public space still lacks attention.

As the only remaining ancient city moat, Donghaochong River condenses the historical development, cultural accumulation and traditional life style of the city. It is where the residents here rest their emotions and seek collective memories [2]. Based on post-occupancy evaluation theory, this research analyzes the internal relationship between continuous improvement of waterfront space environment of Donghaochong River in Guangzhou City and living demand of residents with empirical method, focusing on the following questions: What is the environmental change after reconstruction of Donghaochong River? How do the residents feel and evaluate the waterfront space of Donghaochong River before and after reconstruction? What is the spatial behavior change of residents before and after the reconstruction? How to construct public activity space required by residents in subsequent reconstruction?

\section{Post-Occupancy Evaluation (POE) Method and Content}

\subsection{Post-Occupancy Evaluation Method}

Post-occupancy evaluation is the systematic and strict evaluation process of buildings after they have been constructed and used for a period of time. POE pays attention to the demands of users, the success or failure of building design and the performance of the buildings after completion, all of which shall provide basis and foundation for building design in the future [8]. Post-occupancy evaluation (POE) pays attention to users and usage situation and provides feedback of problems identified during use to the designer to form a good feedback mechanism so as to improve the whole project system [9]. Therefore, POE focuses on users and their demands. By analyzing the influence of previous design decisions and the operation situation of facilities, it provides solid foundation for future design [10]. Being the place and space which provide people with more exchanges, recreations, tours and activities, urban waterfront space has important natural ecological value and social use value. User behavior-oriented evaluation of waterfront space is a effective way to improve the development of waterfront space.

Post-occupancy evaluation of waterfront space includes objective factor evaluation and subjective factor evaluation. Objective factor evaluation means the compliance at functional and technical level with the requirements and specification of use, while subjective factor evaluation is more a kind of expression of standard decided by psychological feelings of people, so it has characteristics of complexity, openness and regionalism, etc. This research conducts post-occupancy evaluation (POE) analysis on the characteristics of waterfront environment of Donghaochong River, the integrated service facility system and the characteristics of user behavior mainly by way of questionnaire, behavior record and interview, obtains the change characteristics of waterfront space of Donghaochong River before and after the reconstruction and summarizes current situation and deficiency so as to provide scientific basis for promoting the quality and management of urban waterfront space.

\subsection{Research Object and Method}

This research chooses Donghaochong River of Guangzhou City as the research object. Donghaochong originates from small rivers alongside Luhu at the southern foot of the Baiyun Mountain, flows through Xiatang West Road to Little North Road and becomes open channel near North Jiaochang Road, flows southward along the Yuexiu Road, and combines with the Pearl River at Dongdi Iron Bridge in the west of Dashatou. Donghaochong River is the center of specific research range which spreads from the Donghaochong River to 500 m residential area. Time for residents arriving at the river is controlled within 10 minutes (the geographic location shows in Figure 1). 
This research is divided into two parts: The first part is research of the current situation of integrated facilities of Donghaochong River. The second part is research of the users of Donghaochong River; the research and analysis is conducted from the structure level, mode of arrival, visiting period, main activities and landscape preference of users. First, research location is selected through exploratory research and preliminary observation for behavior pattern is performed to investigate problems about current situation of use. Then questionnaire survey and field interview is performed. A total of 200 questionnaires are issued. 177 questionnaires are valid, reaching a validity rate of $88.5 \%$. The questionnaire survey adopts subjective evaluation mode combining structure questions and open questions, investigates the advantages, disadvantages and influences after the reconstruction of waterfront space from the point of actual use status, and makes suggestions for late reconstruction and management. Questionnaire survey and field interview is performed, and the target population is the People who live in around ten minutes. The main items of the questionnaire include: Do you think how the water quality of Donghaochong water now compared with the controlled before? What do you think the positive effect of the transform of Donghaochong River improve your quality of life? How often you come here to activities before and after modificantion? If you come here, how long do you spend here on average? etc.

\section{Development Course of Donghaochong River}

\subsection{Evolution of Waterfront Space of Donghaochong River}

"Rivers and streams meandering like alleys forming a net" is a visual description for ancient Guangzhou City with spatial pattern of Lingnan Water Village. Water is the most important environmental factor of Guangzhou City. The Pearl River, as the main vein, plays an important role in water transportation and city image presentation. "River, stream, water and canal" connect to each other to form a net around the city. During the long-term historical development, they not only play a role in water storage and discharge, water traffic and waterborne trade, but also create waterfront living space with strong human interest. As one of "six vein canals"-man-maid drainage system, Donghaochong River originates from the foot of the Baiyun Mountain and connects the Baiyun Mountain and the Pearl River. It was the moat of eastern part of the old Guangzhou City in Ming and Qing Dynasties, forming commercial street city architecture with river as the central part [11]. Thereafter, Donghaochong River became an important traffic channel of Guangzhou City and one of main supply canals for the residents. Sidelines product fair formed on both sides of the river, and street names such as Caomi Lan and Zhu Lan ("Lan" meant fair at that time) were kept to this day. In the Republic of China Period, Guangzhou began to carry out large-scale urban construction activities such as city wall removal and road construction. The city protection function and the canal-supported traffic and commercial street city pattern faded away. With the development of the city, residents began to concentrate along the Donghaochong River. The bank side, bridge head and streets became main public space, where residents gather together for chatting, reading, playing chess and bringing kids to play. By this time, the urban public life along the Donghaochong River formed spontaneously and became richer, becoming important scenes of life of surrounding residents. After the reform and opening up, city development expanded rapidly, population grew dramatically, traffic became busy and environment was damaged too. Donghaochong River gradually became stinking "sewage outfall" [12], and the river-centered public space and scenes of life fade away. In 1993, in order to disperse the south-north traffic in CBD area and old districts of Guangzhou City at the time, the "constructing road over river" plan was put forward, then the present doubledeck Donghaochong Elevated Bridge was built. Urban waterfront area was transformed to traffic space [11], and river bank area declined. In 2009, on the occasion of the Asian Games, Guangzhou City carried out river regulation with a focus on the Donghaochong Old City Reconstruction Project which involved 4 administrative streets and total 230,000 $\mathrm{m}^{2}$ reconstruction land. The change of its waterfront public space affects the city and the public life of people here (Table 1) [2] [13].

\subsection{Research on Interaction of Residents and Rivers}

The interaction of residents and rivers is also the reflection of relationship between human activity and geographical environment and its development and evolution reflects contradictory and coordinative relation among population, resources and environment, therefore it has characteristics of vulnerability, risk, restoring ability and adaptability and is penetrable, changeable and transferable in space dimension and time dimension [14]. The rapid urbanization development and enhanced human capability to transform nature also facilitated the change 


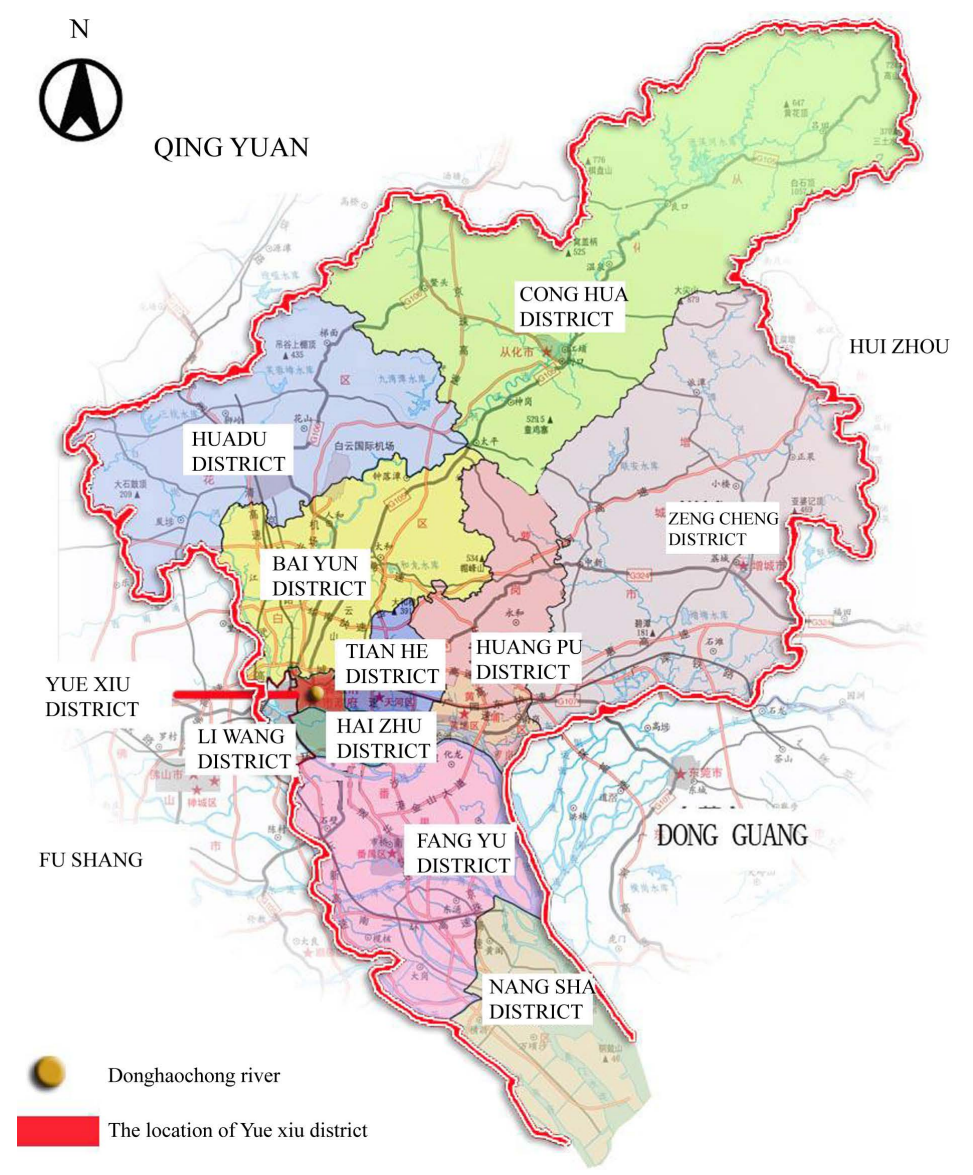

Figure 1. The geographic location of the Donghaochong River in Guangzhou.

Table 1. Evolution course of waterfront space of Donghaochong River ${ }^{1}$.

\begin{tabular}{|c|c|c|c|c|c|c|}
\hline Time & $\begin{array}{c}\text { Before the Ming } \\
\text { Dynasty }\end{array}$ & $\begin{array}{l}\text { Ming and Qing } \\
\text { Dynasties }\end{array}$ & $\begin{array}{c}\text { The Republic of } \\
\text { China }\end{array}$ & $\begin{array}{l}\text { After the founding } \\
\text { of PRC } \\
\text { The reform and } \\
\text { opening up }\end{array}$ & $\begin{array}{c}\text { From the reform and } \\
\text { opening up to } 2010\end{array}$ & After 2010 \\
\hline Functions & $\begin{array}{c}\text { Moat } \\
\text { Drainage canal }\end{array}$ & $\begin{array}{l}\text { Drainage and } \\
\text { supply canal } \\
\text { Caomi Lan }\end{array}$ & $\begin{array}{l}\text { Living river } \\
\text { Water traffic }\end{array}$ & $\begin{array}{c}\text { Transportation } \\
\text { Household by the } \\
\text { river }\end{array}$ & $\begin{array}{l}\text { Pollution discharge } \\
\text { Dilapidation }\end{array}$ & $\begin{array}{c}\text { Drainage } \\
\text { Watching and } \\
\text { entertainment }\end{array}$ \\
\hline $\begin{array}{l}\text { Construction } \\
\text { situation on } \\
\text { both sides }\end{array}$ & $\begin{array}{l}\text { Open countryside } \\
\text { on both sides }\end{array}$ & No construction & $\begin{array}{c}\text { Covered with } \\
\text { self-constructed } \\
\text { houses }\end{array}$ & $\begin{array}{c}\text { Buildings on both } \\
\text { sides become dense } \\
\text { gradually }\end{array}$ & $\begin{array}{l}\text { Large-scale } \\
\text { construction, many } \\
\text { high buildings rise }\end{array}$ & $\begin{array}{c}\text { Restore the } \\
\text { environment on both } \\
\text { sides, and increase } \\
\text { green space }\end{array}$ \\
\hline $\begin{array}{c}\text { Type of urban } \\
\text { public } \\
\text { activity }\end{array}$ & None & None & $\begin{array}{l}\text { Water traffic and } \\
\text { waterborne trade } \\
\text { Leisure activity and } \\
\text { fair along the river }\end{array}$ & $\begin{array}{l}\text { Leisure activity along } \\
\text { the river } \\
\text { Fair along the river }\end{array}$ & Fade away & $\begin{array}{c}\text { Revive original } \\
\text { activities } \\
\text { Develop some new } \\
\text { activities. }\end{array}$ \\
\hline $\begin{array}{l}\text { Typical } \\
\text { images }\end{array}$ & & & & & & \\
\hline
\end{tabular}

${ }^{1}$ Drawn by the author, Pictures 1-4 cited from http://blog.sina.com.cn/u/2161557144, Pictures 5-6 photographed by the author. 
of relationship between human and river. The relationship between Donghaochong River and surrounding residents underwent three main stages:

1) Harmonious coexistence stage (before 1987)

Before the reform and opening up, Donghaochong River was closely bound up with people's daily lives. It was not only the main drainage canal in Guangzhou City but also the back alley for the lives of residents. Water intake, washing, trip, tour and other activities were undertaken by the river. The river-centered landscapes"small river, small boat, stone bridge and banyan" form typical style of Lingnan water village. Human activities formed spontaneously in this stage were basically within the carrying range of ecological environment of rivers. Rivers were the most important public space for the communication of neighborhood and the living and leisure of residents, condenses the historical development, cultural accumulation and traditional life style of the city. Harmonious coexistence relation between human and river was established.

"We took drinking water, washed rice and washed clothes here, children also swam here at that time"

- Ms. Wang, a resident by the river (over 50 years old)

"I often played in this river when I was a kid, especially having water fight with my friends. I still feel very happy when thinking of this now."

2) Isolation and opposition stage (1987-2008)

$\mathrm{Mr}$. Li, a resident by the river (over 30 years old)

After the reform and opening up, rapid urbanization highlighted the issues of high building density, population density and traffic density. To relieve the traffic predicament of the time, the government put forward "constructing road over river" plan and built the double-deck Donghaochong Elevated Bridge, which played an important role in dispersing the south-north traffic of the old city but which also led to the transformation and marginalization of waterfront space of the river. Being the only natural drainage channel of production and domestic sewage, Donghaochong River was experiencing serious aggradation and pollution, and some areas even showed water quality-induced water shortage. The deterioration of river environment made the life of residents on the two sides of the river so miserable that they have to withdraw actively or passively. The relation between human and river moved towards opposition and isolation.

"The river was very stinky at that time, we dared not open the window, let alone coming out..."

Mr. Liu, a resident by the river (over 50 years old)

"The river was so clear in the past that we can catch fishes and shrimps, but then it turned very stinky, fishes and shrimps died out, and people dared not to go close to it..."

3) Restoration and improvement stage (2009-now)

-Mr. Zhang, a resident by the river (over 60 years old)

To a large extent, Donghaochong River acted as the heterogeneous space and environment symbol for social development, therefore, the improvement of its ecological environment enabled the restoration and continuation of social network structure of neighborhood. After 2009, on the occasion of the Asian Games, Guangzhou City carried out city image renewal and environment reconstruction. The landscape function and leisure recreation function of Donghaochong River was rediscovered. In the regulating process, houses covering an area of about $48,000 \mathrm{~m}^{2}$ on both sides were demolished, waterfront landscape and leisure zone and public green square were built under the elevated bridge across the river, a $5.1 \mathrm{~km}$ matching greenway was constructed along the distance from Luhu to Yanjiang. River landscape was greatly improved in the urban environmental construction activity, and the relation between human and river was also being improved continuously in dynamic state.

"Now the environment here is much better, water of the river is also much clearer. We often bring the kids here to play or have a chat with the old neighbors."

Granny Luo, a resident by the river (over 70 years old)

"I always come here doing some exercise when I'm free. The environment is much more beautiful than the past, but I think it can be better, I hope the water can be clearer.

— Ms. Jiang, a resident by the river (over 40 years old)

\subsection{State of the Environment of Donghaochong River after Reconstruction}

After comprehensive reconstruction of humanities, ecology and environment, Donghaochong River not only achieved the functional conversion from single closed drainage system to landscape water environment which combines horizontal comprehensive utilization but also achieved several reconstruction goals such as natural community reproduction, ecological environment upgrading, visual landscape beautifying and enabling to play 
in water. With the goal of "interaction of rivers and human”, by combining the historical and humanistic customs and taking the activity demand of citizens into account, the government proposed to reproduce the social function of waterfront space and form new water culture of Guangzhou City. Therefore, on the basis of water management of Donghaochong River, facilities such as water platform and green square were mainly added to create water accessible public activity space for citizens. River-themed museum and water control inscription were built, famous historical bridges were restored and small modern brides were built, and landscape nodes such as cascading waterfall, theme sculpture, pavilion, post house and leisure square were also set along the river. Besides, landscape greenway was set along Donghaochong River. The continuous configuration on both sides of the road, combining the green landscape along the river, greatly improved the whole landscape and provided a more comfortable residential environment. With respect to supporting facilities, Donghaochong River is equipped with 1 bicycle post house, 9 leisure post houses, 4 basketball courts, 5 badminton courts and table tennis courts, 5 fitness centers, 100 fitness equipments and 6 public toilets (Figure 2). Integrating ecological landscape, entertainment and bodybuilding, Donghaochong River after reconstruction has become a compressive place for leisure activity which meets residents' demand for quality life. Such positive change not only shall affect the outer feeling of residents but also shall definitely cause their inner emotional change. The analysis of characteristic landscape is shown in Table 2.

\section{Evaluation for Usage Situation of Residents before and after Reconstruction of Donghaochong River}

\subsection{Comparison of Activity Resident Constitution before and after Reconstruction of Donghaochong River}

1) Activity residents changes from single type to diversified types. Table 3 illustrates that middle aged and elderly people are the main mobile population type before reconstruction of Donghaochong River. The population structure was single and unstable, attaching environment was lacked, and the intervention of population was weak; but after reconstruction of Donghaochong River, the proportion of young people in the mobile population increased obviously. Among 177 users being investigated, many are young people under 18 years old. The rich and relatively even age structure shows that the reconstruction expanded the radiation range of Donghaochong River, improved the attraction for population, and promoted exchanges between people.

2) Activity of residents changes from individual activity to group activity. Before reconstruction, residents usually passed by Donghaochong River alone or when they went to/got off work with their colleagues; but the beautiful environment today has attracted many residents inviting their family, neighbors or friends to play here. The activity of residents has changed from individual to group, and the relation between residents also gets improved. More interpersonal relationships are being developed continuously in the public space.

\subsection{Comparison on How Long Residents Use Donghaochong River before and after Reconstruction}

1) Activity frequency of residents rises significantly. A set of curves clearly reflect that: before reconstruc-

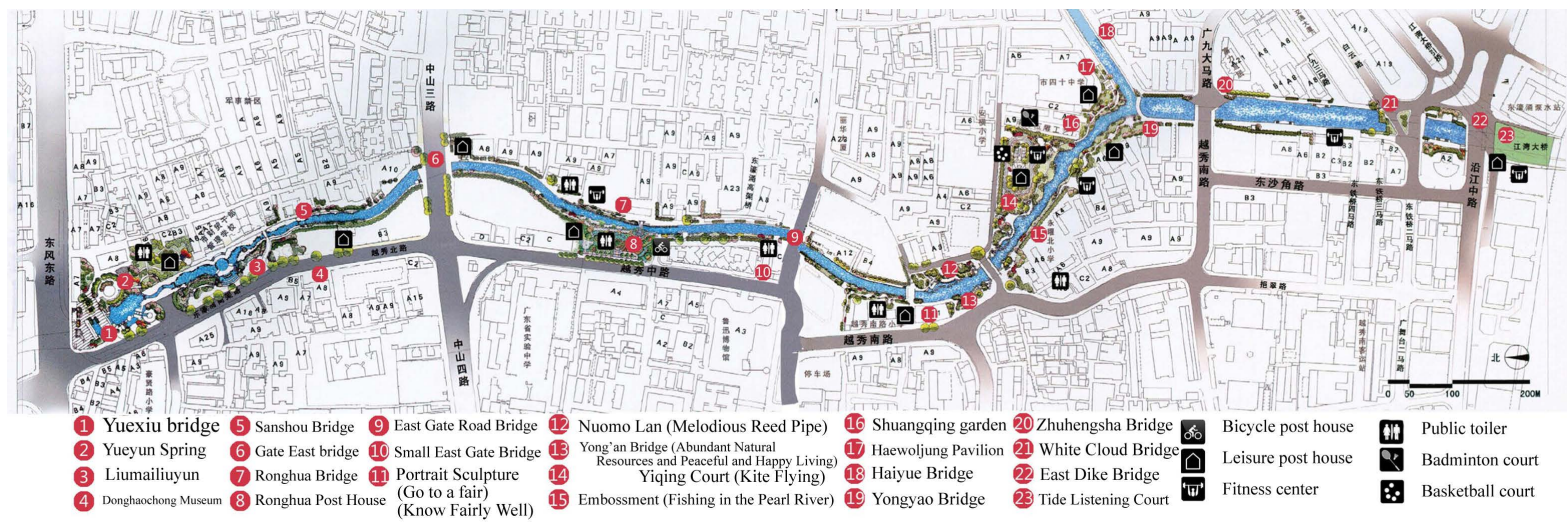

Figure 2. Distribution of existing supporting facilities and landscapes at open channel section of Donghaochong. 
Table 2. Analysis on characteristic landscape element of Donghaochong River after reconstruction.

\begin{tabular}{|c|c|c|c|c|c|c|c|}
\hline Type & Bridge & Water platform & Greenway & Green square & $\begin{array}{l}\text { Accessories/ } \\
\text { sculpture }\end{array}$ & Sports place & $\begin{array}{l}\text { Recreational } \\
\text { facilities }\end{array}$ \\
\hline $\begin{array}{c}\text { Feature } \\
\text { introduction }\end{array}$ & $\begin{array}{l}14 \text { bridges } \\
\text { One bridge is } \\
\text { one landscape } \\
\text { Each has a story }\end{array}$ & $\begin{array}{c}\text { Clear water } \\
\text { Natural ecology } \\
\text { Lingnan style }\end{array}$ & $\begin{array}{l}4.51 \mathrm{KM} \text { long } \\
\text { Constructed next } \\
\text { to the river } \\
\text { Green gallery }\end{array}$ & $\begin{array}{l}\text { Wide and open } \\
\text { Diversified } \\
\text { Green coverage }\end{array}$ & $\begin{array}{l}\text { Guangzhou } \\
\text { culture } \\
\text { Memory of the } \\
\text { ancient city } \\
\text { Numerous }\end{array}$ & $\begin{array}{l}\text { Good facilities } \\
\text { Uniform } \\
\text { distribution } \\
\text { Accessible }\end{array}$ & $\begin{array}{c}\text { Arranged along } \\
\text { the river } \\
\text { Various shapes } \\
\text { Simple and } \\
\text { natural }\end{array}$ \\
\hline Typical images & & & & & & & \\
\hline
\end{tabular}

Table 3. Comparison of activity resident constitution before and after reconstruction.

\begin{tabular}{cccccccccccc}
\hline Project & \multicolumn{3}{c}{ Age structure comparison (\%) } & \multicolumn{5}{c}{ Companionship situation comparison (\%) } \\
\hline & $\begin{array}{c}0-20 \text { years } \\
\text { old }\end{array}$ & $\begin{array}{c}21-40 \\
\text { years old }\end{array}$ & $\begin{array}{c}41-60 \\
\text { years old }\end{array}$ & $\begin{array}{c}\text { Over } 60 \\
\text { years old }\end{array}$ & Alone & Family & Friends & Neighbors & Colleagues & Others \\
\hline $\begin{array}{c}\text { Before } \\
\text { reconstruction } \\
\text { After }\end{array}$ & 8.41 & 16.79 & 35.11 & 39.69 & 27.48 & 13.74 & 9.92 & 12.98 & 22.14 & 13.74 \\
reconstruction & 27.88 & 33.94 & 16.97 & 21.21 & 10.90 & 27.27 & 21.83 & 20.00 & 13.94 & 6.06 \\
\hline
\end{tabular}

tion, residents who never come to Donghaochong River accounts for half and residents who come to Donghaochong River accounts for only 5\%; after reconstruction, the percentage of residents who come to Donghaochong River more than 3 days (including 3 days) a week reaches $70 \%$ and the percentage of residents who occasionally come to and never come to Donghaochong River also reduces to less than $10 \%$. The summary statistics are presented in Table 4.

2) Residence time of residents increases significantly. By comparing the average duration of residents who come to Donghaochong River before and after reconstruction, it is found that: before reconstruction, resident activity is short and fast. Activity duration of 70\% residents doesn't exceed 1 hour; after reconstruction, resident activity is longer. The percentage of residence time more than 1 hour is improved greatly (Table 4).

\subsection{Comparison of Activity Content of Residents before and after Reconstruction of Donghaochong River}

1) Activity content changes from just passing by to diversified activities. Before reconstruction, over $50 \%$ of the activity content of residents is just passing by, which is much higher than the percentage of other activities. Activity type is single and vapid; after reconstruction, the percentage of doing exercises, chatting, playing cards, accompanying children or elders rises significantly. Besides, such activities are relatively even, and the type is diverse. The change of environment improves the function of Donghaochong River, and thereby its role as urban public space is truly played.

2) Public facilities decide activity content. Before reconstruction, dirt and stinky water in Donghaochong River is the main reason why residents were unwilling to come here; after reconstruction, however, road and infrastructure becomes the main obstruction. Ms. Chen said, "Cars passing by and the complex road make here very dangerous, so I generally just bring the kids to take a walk here. If the road condition is improved and some children entertainment facilities are added, I will be willing to take the kids to play freely here and not just walk”. This shows that activity content is influenced by public facilities. 
Table 4. Comparison of use time of activity residents before and after reconstruction.

\begin{tabular}{cccccccccc}
\hline & \multicolumn{3}{c}{ Resident activity frequency comparison (\%) } & \multicolumn{4}{c}{ Residence time comparison (\%) } \\
\cline { 2 - 10 } Project & Every day & $\begin{array}{c}\text { Three days a } \\
\text { week }\end{array}$ & $\begin{array}{c}\text { Every } \\
\text { weekend }\end{array}$ & Occasionally & Never & Over 2 h & 1 - 2 h & $0.5 \mathrm{~h}$ & Under 0.5 h \\
$\begin{array}{c}\text { Before } \\
\text { reconstruction }\end{array}$ & 5.08 & 11.30 & 10.74 & 25.99 & 46.89 & 2.26 & 5.08 & 16.95 & 75.71 \\
$\begin{array}{c}\text { After } \\
\text { reconstruction }\end{array}$ & 31.07 & 38.98 & 12.99 & 6.78 & 10.17 & 19.21 & 31.07 & 36.16 & 13.56 \\
\hline
\end{tabular}

\subsection{Comparison of Overall Experience of Residents before and after Reconstruction of Donghaochong River}

1) Reconstruction effect is accepted by most residents; the reconstruction has a positive effect on the lives of residents. Table 5 shows that over $80 \%$ residents are satisfactory to the overall reconstruction of Donghaochong River and think the reconstruction has a positive effect on their lives. In the interview, residents also show recognition and agreement with the reconstruction effect. The various leisure facilities get a satisfaction degree of $27.17 \%$ which is the highest, followed by fitness and entertainment facilities which get a satisfaction degree of $23.12 \%$. However, service facilities, sanitation facilities and barrier-free facilities get relatively poor satisfaction degree.

2) River regulation doesn't show obvious effect and causes certain damages, so improvement is needed. Although over RMB 1 billion was invested in Donghaochong River reconstruction project, residents state that there still are overflowing and silt accumulation problems after reconstruction, the maintenance of which need massive funds. Most residents think that, the reconstruction period is long, but the reconstruction effect is not so obvious. Furthermore, some residents find that certain damages were caused during the reconstruction. Largescale house demolition will certainly generate new contradictions. How to deal with the relation between residents and the river and give full play to the advantages and value of the river while carrying out reconstruction is the main task at present.

\section{Conclusions and Suggestions}

\subsection{Conclusions}

The public property of urban waterfront space has become social consensus and the popularization level of public space has become the symbol determining social development and civilization level, therefore, the reconstruction and renewal of rivers should comply with the characteristics and rules of human activities. The research and interview shows that the public space of the river and the usage situation of residents before and after reconstruction undergo the following changes:

1) After reconstruction, Donghaochong River expands the leisure time and space of surrounding residents. After reconstruction, by improving water quality, providing recreation opportunity and improving aesthetic value, there is a public space for activity, recreation and meeting to expand the leisure time for the surrounding residents, and improve the quality of the lives of residents.

2) High quality waterfront space can provide good behavioral environment. According to comparison of using population before and after reconstruction, more diversified population chooses to come to Donghaochong River to have a leisure time and tour and the type of activity gets more diversified. This shows that the indexes of various elements of Donghaochong River are improved after reconstruction to attract residents of surrounding communities to stay here and the exchange between people is enhanced.

3) The lack of supporting facilities has a great effect on the use of waterfront space. Supporting facilities are the carrier and guarantee for citizens carrying out diversified leisure activities smoothly. At present, most leisure activity spaces of Donghaochong River are for simple activities such as walking and chatting. If diversified supporting facilities can be built according to the need of different groups, the leisure activity of surrounding residents will be more enriched and diversified.

4) Reconstruction effectiveness and later-stage maintenance and management needs to be strengthened. 
Table 5. Analysis on satisfaction degree after reconstruction.

\begin{tabular}{|c|c|c|c|c|c|c|c|c|c|c|c|}
\hline \multirow{2}{*}{ Project } & \multicolumn{5}{|c|}{ Overall satisfaction degree (\%) } & \multicolumn{6}{|c|}{ Satisfaction degree for various supporting facilities (\%) } \\
\hline & $\begin{array}{c}\text { Quite } \\
\text { satisfied }\end{array}$ & $\begin{array}{l}\text { Basically } \\
\text { satisfied }\end{array}$ & General & $\begin{array}{c}\text { Basically } \\
\text { dissatisfied }\end{array}$ & $\begin{array}{c}\text { Quite } \\
\text { dissatisfied }\end{array}$ & $\begin{array}{c}\text { Fitness } \\
\text { facilities }\end{array}$ & $\begin{array}{c}\text { Service } \\
\text { facilities }\end{array}$ & $\begin{array}{c}\text { Rest } \\
\text { facilities }\end{array}$ & $\begin{array}{c}\text { Sanitation } \\
\text { facilities }\end{array}$ & $\begin{array}{c}\text { Barrier-free } \\
\text { facilities }\end{array}$ & Others \\
\hline $\begin{array}{c}\text { After } \\
\text { reconstruction }\end{array}$ & 26.37 & 42.14 & 19.48 & 7.39 & 4.62 & 23.12 & 17.61 & 27.17 & 14.32 & 9.06 & 8.72 \\
\hline
\end{tabular}

Donghaochong River, where overflowing occurs every time when rainstorm pours down, is a star project regulated repeatedly in recent years. Poor reconstruction effectiveness is closely bound up with the water management thought and experience of relevant department. It is also one of restrictive factors for river reconstruction. Meanwhile, due to the lack of later-stage maintenance and management, uncivilized behaviors such as pets' open defecation behavior and residents' stepping on the grass behavior aren't held back by management personnel, causing a serious effect on the green landscape which is in good condition at present.

\subsection{Suggestions}

As moat of the city, Donghaochong River has deep historical accumulation. It is the space carrying the texture and historical context of old Guangzhou City. Therefore, the transformation of material space shall focus on reflecting historical connotation and value, complying with the demand of modern culture life and achieving the balance of natural ecosystem, stimulate the vitality of the old city by taking river reconstruction as the "catalysis space" of urban overall space development and thus promote the harmonious development of old city renewal and new city construction. Currently, although river reconstruction has obtained certain effect and satisfaction, the humanization quality of public space environment is not so good, and the comprehensive control of water environment of waterfront system needs to be enhanced specially, including solving problems at technical level such as sewage interception, desilting, water purifying and embankment regulation. Meanwhile, the reconstruction of activity facilities, landscape greening and diversified water landscape of river waterfront space shall be strengthened, the relation between human and river and the broken water culture history shall be restored and a vigorous urban waterfront space environment shall be rebuilt so as to provide high quality waterfront activity space for Guangzhou citizens.

\section{Image Source}

Figure 1 and Figure 2 are drawn by the author.

Pictures 1-4 in Table 1 are cited from http://blog.sina.com.cn/u/2161557144.

Pictures 5-6 in Table 1 and Pictures 1-14 in Table 2 are photographed by the author.

\section{Foundation Projects}

National Natural Science Foundation of China (No. 41301175).

Characteristic and Innovation Project of Humanities and Social Sciences of Ordinary Universities in Guangdong Province (No.: 2014WTSCX030).

Open Project of State Key Laboratory of Subtropical Building Science (No. 2013KB16).

Public Interest Research and Capacity Building Project of Special Fund in Guangdong Province (No. 2015A020219007).

\section{References}

[1] Zhong, Y. (2013) A Study on the Problems and Strategies of Eco-Environment Construction in Urban Renewal. Modern Urban Research, No. 12, 84-88.

[2] Pan, J.F. (2012) A Study on Water System Renovation in the Central District of Old City Based on Urban Regeneration: Taking Lychee Wan Creek and Donghaochong River as Example, Guangzhou. Chinese Landscape Architecture, No. 3, 62-65.

[3] Zhai, B.Q. and Mee, K.N. (2009) Urban Regeneration and Its Realities in Urban China. Urban Planning Forum, No. 2, 75-82. 
[4] Chen, K.L., Xue, D.S. and Wang, X. (2012) Research on River Environment in Wuyanqiao Bridge River Area in Guangzhou City in the Context of Rapid Urbanization: Microcosmic Perspective Based on Human Activity Transition. Human Geography, 27, 67-72.

[5] Tang, Y.F. (2010) Some Enlightenment from the Experience in River Regulation in Guangzhou during the Period of the Republic of China. Tropical Geography, 30, 322-326.

[6] Sun, Y.J., Cen, H.X. and Wang, S.G. (2009) Environmental Sociology Thoughts of Urban River Reconstruction under Human-Water Harmonization Concept. Guangzhou Environmental Sciences, 24, 30-34.

[7] Jin, H.X. (2009) The Strategies of the Planning and Designing for the Waterside Landscape of the Rivers and River Branches in Guangzhou. Guangdong Landscape Architecture, 31, 49-52.

[8] Preser, W.F.E., Rabincwitz, H.Z. and White, E.T. (1988) Post-Occupancy Evaluation. Van Nostrant Reinhold, New York, 39-46.

[9] Zhao, D.H. (2007) Research on the Development of Post Occupancy Evaluation (POE) Abroad and Its Feasibility in China. Acta Scientiarum Naturalium Universitatis Pekinensis, 43, 797-802.

[10] Wolfgand, F.E.P., Harvey, Z.R. and Edward, T.W. (1998) Post Occupancy Evaluation. Van Nostrand Reinhold Company, New York.

[11] Huang, X. and Shen, K. (2009) Decline and Regeneration of the Communal Space in the Donghao Area of Guangzhou. Urbanism and Architecture, No. 2, 54-56.

[12] Ren, X.Y. (2012) Analysis on the Impact to City Public Life by the Change of Guangzhou Urban Creek Landscape: Take the Case of Donghaochong. Journal of Guangdong Landscape Architecture, No. 2, 37-39.

[13] Li, Q. and Shen, H. (2011) The Renovation of the Landscape Environment in the Riverfront of Guangzhou Central City. Chinese Landscape Architecture, No. 7, 7-12.

[14] Shi, P.J., Wang, J.A., Chen, J., et al. (2006) The Future of Human-Environment Interaction Research in Geography: Lessons from the 6th Open Meeting of IHDP. Acta Geographica Sinica, 61, 115-126.

\section{Submit or recommend next manuscript to SCIRP and we will provide best service for you:}

Accepting pre-submission inquiries through Email, Facebook, LinkedIn, Twitter, etc.

A wide selection of journals (inclusive of 9 subjects, more than 200 journals)

Providing 24-hour high-quality service

User-friendly online submission system

Fair and swift peer-review system

Efficient typesetting and proofreading procedure

Display of the result of downloads and visits, as well as the number of cited articles

Maximum dissemination of your research work

Submit your manuscript at: http://papersubmission.scirp.org/ 